\title{
Project-Based Learning Technology: An Example in Programming Microcontrollers
}

\author{
https://doi.org/10.3991/ijet.v15i11.13267 \\ Zhanat Nurbekova, Talant Tolganbaiuly ${ }^{(凶)}$, Bahyt Nurbekov \\ L.N. Gumilyov Eurasian National University, Nur-Sultan, Kazakhstan \\ talant2101@gmail.com \\ Ainur Sagimbayeva \\ Abay Kazakh National Pedagogical University, Almaty, Kazakhstan \\ Zhadira Kazhiakparova \\ West Kazakhstan Innovation Technology University, Uralsk, Kazakhstan
}

\begin{abstract}
This article presents the technology of the organization of projectbased learning in programming microcontrollers based on the faculty of information technology L.N. Gumilyov Eurasian National University. Based on the analysis of scientific, methodological and normative articles, a structural model of the organization of the project-based learning in programming microcontrollers was developed. The processes of project development life cycle and the role of each member of the project team were described by stage. In the process of developing the project, students faced various challenges and found ways to solve them. As a result of the project-based seminars, the participants learnt to apply theoretical knowledge to solve real world problems in practice and received an unforgettable experience working in team.
\end{abstract}

Keywords-Project-based learning, Arduino microcontroller, projects, programming microcontrollers.

\section{Introduction}

Teaching of a programming of microcontrollers has an applied character and involves the implementation of training projects. Work on projects using microcontrollers enables the teacher realizing educational goals by attracting knowledge from other areas (programming, physics, mathematics, mechatronics, electronics and others), to introduce creativity into the educational process [1].

The analysis of the current state of teaching in higher education in the context of digitalization [2-3] showed that project-based learning should not be considered in the form that has been available in traditional pedagogy since the last century. The format of the organization of project training requires a change, taking into account modern digital tools and time management. Research Methodology and Design 
This article presents the experience of organizing a project-based learning in the programming of microcontrollers. Based on the analysis of scientific, methodological and normative documents [4-14], educational activities in microcontroller programming were systemized, which determined the need for structuring educational activities in accordance with the project activities in the design of technical systems (Figure 1).

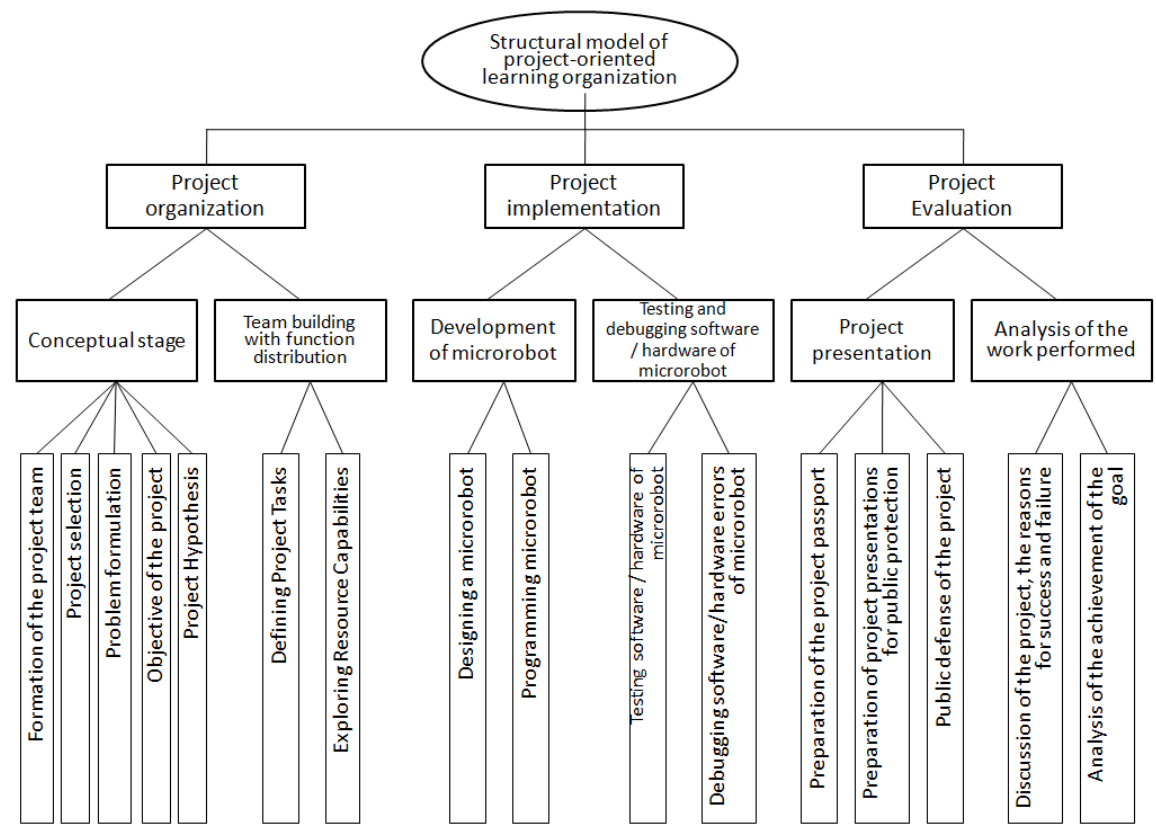

Fig. 1. Structural model of the organization of the project-based learning instruction in programming microcontrollers

\section{Results}

Let us consider a block structural model of the organization of the project-based learning instruction in microcontrollers programming. According to the block named "Organization of the project" at the beginning of the project there was formed a group of students taking into account their interpersonal relations and interests. When forming a project team, depending on the specifics of the project, the composition of the project team was determined: project manager, engineer, and programmer.

There was performed a selection of the project taking into account the characteristics of the basic components of the microcontrollers. As the training platform, we chose the Arduino microcontroller. The distinctive features of the Arduino microcontroller are simple and understandable programming environment Arduino IDE, cross-platform and open source software [15]. Therefore, projects based on the Arduino microcontroller were proposed: "Smart parking", "Smart garden", "Smart home". The topic of the 
project "Smart parking" was chosen in accordance with the collective interests and individual characteristics of students.

The problem statement was developed during the discussion of the project, taking into account digitalization and solving urban problems. The project team decided to solve the problem of overflowing city car parks.

Thus, the goal of the project is: development of the "Smart parking" based on the Arduino microcontroller.

In accordance with the goal of the project, the following hypothesis was formed: if you automate parking based on systems to notify drivers of available seats, it is possible to control the occupancy rate of city car parks and optimize the use of parking lots.

In accordance with the features of the work carried out within the project the next step was to determine the structure of work. The participants of the project team identified the tasks of the project and, depending on the skills and knowledge of each student, assigned tasks to each other:

- Collection and study of information about parking places in the country, current status and functionality (group work; $1^{\text {st }}$ lesson)

- Determination of the functionality and appearance of the project (group work; $1^{\text {st }}$ lesson)

- Design of the project "Smart parking" (engineer; $2^{\text {nd }}$ lesson)

- Programming of sensors, servos and other details of the project "Smart parking" (programmer; $2^{\text {nd }}$ lesson)

- Testing and debugging of the software and technical parts of the project (group work; $2^{\text {nd }}$ and $3^{\text {rd }}$ lessons)

- Preparation of the passport and project presentations for public protection (group work; $4^{\text {th }}$ lesson)

- Public protection of the project (group work; $5^{\text {th }}$ lesson).

In total, the implementation of the trial project took 5 lessons. The duration of each lesson was 50 minutes. Most of the time was used to develop and test the project.

The study of the resource capabilities of the microcontroller is one of the important stages of the project. In the previous stages, the project participants studied the object of study and determined the main functions of the parking (Figure 2):

\begin{tabular}{||c|c|}
\hline The main functions of «Smart parking» \\
\hline $\begin{array}{c}\text { Subsystem of } \\
\text { remote control of } \\
\text { parking barrier }\end{array}$ & $\begin{array}{c}\text { Subsystem of } \\
\text { control and display } \\
\text { of free parking } \\
\text { spaces }\end{array}$ \\
\hline \hline Automatic lighting \\
control subsystem & $\begin{array}{c}\text { Parking } \\
\text { temperature and } \\
\text { humidity monitoring } \\
\text { subsystem }\end{array}$ \\
\hline
\end{tabular}

Fig. 2. The main functions of the "Smart parking" project 
Sensors, servomotors, displays and other components of the Arduino microcontroller were previously selected and studied for implementation of the above-mentioned functions of the parking.

- Distance sensors: ultrasonic distance measuring module HC-SR04, ultrasonic distance measuring module US-015, ultrasonic range finder US-100 with UART interface

- Temperature and humidity sensors: DHT11 temperature and humidity sensor on the board, DHT22 temperature and humidity sensor on the board

- Light sensors: photoresistor GL5516, GL5506, GL5528

- Servo motors: Micro H301 servo motor, SG92R servo motor

- Graphic LCD display: 1602 display, I2C module for 1602 LCD display

- Control modules: IR remote with control board on the HX1838.

Consider the second block of the structural model of the organization of a projectbased learning of programming microcontrollers named "Project Implementation". At the beginning of the project, a vision has already been formed on how the parking place would look like, what it would consist of and what functions it would perform. The project participants studied the capabilities of the Arduino microcontroller, and selected the necessary details for the implementation of the project. The student, playing the role of the engineer, used the following details for the construction of the project $[16,17]$ :

- SG92R servo was selected as a parking barrier

- Ultrasonic distance measuring modules HC-SR04 were used to monitor and display the available parking spaces. The number of parking spaces is 4 , respectively 4 units of this sensor were connected

- The automatic lighting control subsystem was implemented using a light sensor the photoresistor GL5516

- A temperature and humidity sensor DHT11 were used to monitor the temperature and humidity of the parking

- A display 1602 with the module I2C was selected to indicate the received data from the sensors.

The organization of energy supply for the project was handled in such a way that each of the above parts were connected using a breadboard, therefore, power and control were carried out using the Arduino microcontroller.

When designing a project, the following principles were followed:

- Mobility (the project should be lightweight; the details of the project should be easily attached to each other)

- Reliability (project parts and other elements must be durable)

- Extensibility (it should be possible to add additional parts and components to expand the functionality of the project).

After completing the parking assembly, a student, programmer, developed the code for the Arduino microcontroller. Instructions and conditions for each sensor on the device were implemented based on the functionality of the parking. 
Micro H301 servo drive was used as a parking barrier. Barriers serve to restrict entry to the parking lot, so when the servo shaft rotates 90 degrees, the barrier opens and the green light-emitting diode turns on with an interval of 3 seconds. Then we return the servo shaft back to 0 degrees, the barrier closes and the red light-emitting diode turns on, giving a stop signal to car drivers.

To control the barrier, students connected an infrared remote control with HX1838 control boardl

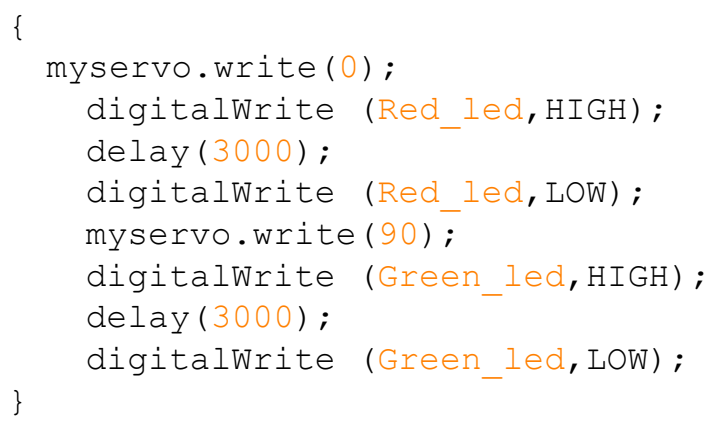

The program code developed to control the infrared remote control with the HX1838 board is designed to open and close the barrier (by pressing the volume buttons on the infrared remote control). Therefore, an increase in volume - opens the barrier, a decrease in volume - closes the barrier.

An ultrasonic distance measurement module was used to monitor and display the available parking spaces. The control code of the ultrasonic distance measuring module is implemented as follows: if at least one obstacle was encountered at a distance of 30 $\mathrm{cm}$ in 4 ultrasonic distance measuring modules, the message "no free places" was sent to the display;

The program code of the light sensor - photoresistor GL5516 work as follows: while the room is light, the light-emitting diode turns off, but as soon as the light level falls below a certain value $(<900)$, the light-emitting diode turns on.

A snippet of the program code for displaying all data from various sensors of LCD display:

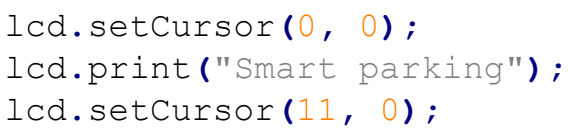

During the implementation of this phase of the project, a number of problems related to sensor libraries, compatibility with versions of the software environment, and the indication of several indicators from various sensors in one display were solved.

Testing and debugging of the parking software and hardware was carried out by student members of the project team. Devices with various factors have been tested. A performance of the sensors, servo drive and display were checked. As an example, the DHT11 temperature and humidity sensor was tested using fire. If you strike a match or 
lighter near the sensor, the temperature display showed a high level. Thus, it was concluded that the operability of the sensor is in good condition.

In the process of testing the device, the location of the sensors was changed, and the power sources were centralized.

"Project Evaluation" is the final block of work of the structural model for organizing the project-based learning instruction in programming microcontrollers.

The preparatory stages of project protection include: creating a passport and project presentations. Students together with the teacher prepared a project passport. This document contains main characteristics of the project. The key requirement in preparing the project passport is a detailed description of the work performed by each student in the project team.

Upon completion of the preparation of the project passport, the project team proceeded to the development of project presentations for the defense in front of the public [18]. At this stage, students selected material for presentation. The normal number of slides is 9-12. Attention should be paid to the ergonomics of slides when developing presentations. Recommendations were made on creating presentations: a maximum of 3-4 colors on a slide; there shouldn't be a lot of text on the slide; text and images should be aligned; only high-quality images should be used.

A prerequisite for the implementation of project-based learning in the programming of microcontrollers is a successful presentation pitch of the created product. Students defended the project in front of university professors. During the presentation, the participants adhered to the principles of brevity, consistency and effectiveness. The developers have clearly demonstrated all the functionalities of "Smart parking".

Public presentation of projects was successful, all groups coped with their tasks. The works were marked according to evaluation criteria. Evaluation criteria consisted of two parts: evaluation of the work itself and defending presentations in front of the audience. The evaluation system of the project itself was developed taking into account its goals, objectives, conditions and considered several aspects such as: relevance and novelty of the proposed solutions; the practicality of the project (mobility, reliability and extensibility); student independence level; optimality of the ratio of required resources and results. The criteria for assessing the protection of presentations to the audience were the following: artistry and expressiveness of the participants' performance, the quality of the multimedia presentation, and the accuracy and completeness of the answers to the questions [19].

\section{Discussion}

Before the project evaluation the checklists named "Project evaluation" were issued for the jury (teachers). The data on points for each position was given. Based on the set of points, a general assessment of the project work of students was formed. For example:

- The "Smart city" project. The project scored the highest amount of points (96\%). The participants performed at a high level, carefully demonstrated the work of parking, the presentation of the project was visual. The implementation of the 
"demonstration of free parking spaces" subsystem aroused great interest in the audience.

- The "Smart garden" project. The total score of the project is $89 \%$. There was a comment on the item "The practicality of the project (mobility, reliability, extensibility)". In particular, the system of "watering plants", the location of the sensors, wires and display was in doubt. The reliability of the project was a big question, since there could be a closure of the components of the microcontroller.

- The "Smart home" project. The final result of the project is $87 \%$ (Figure 3). In this digital age this project is very relevant. The project is assembled very carefully and reliably. Unfortunately, the participants did not use all of the Arduino microcontroller's capabilities; the functionality of the project was limited.

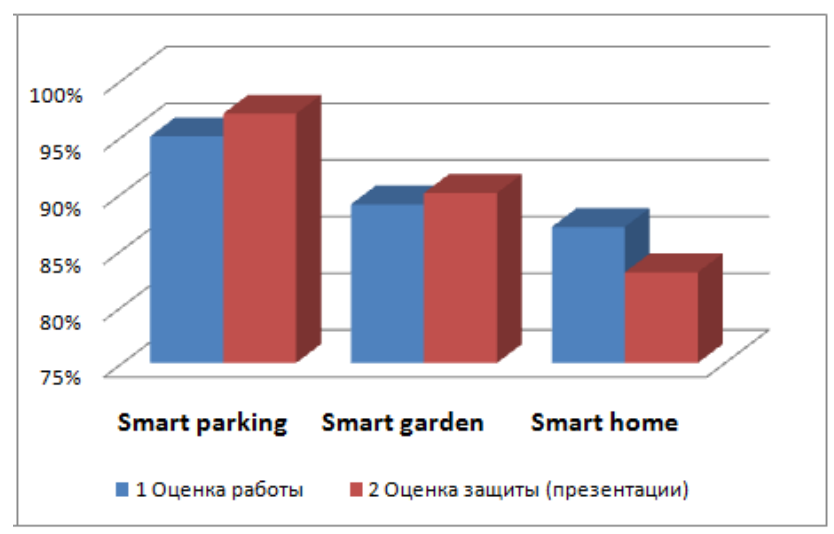

Fig. 3. Project Evaluation Results

After defending the project, students asked questions and received answers, discussed the work of project teams. The main goal of this process was to identify the strengths of the developed product, and to determine the points that require refinement.

The project team determined the project development perspective:

- Improve the parking with the SMS notification system for parking customers about the availability of free parking spaces on the mobile phone

- Add a car counter function based on a seven-segment indicator at the entrance to the parking lot.

In accordance with the goal of the project, all the tasks outlined were implemented. In the process of developing the project, students faced various difficulties and found ways to solve them. For example, when developing the "Smart parking" project, students were faced with the problem of connecting and programming an LCD display to display data. The project team engineer connected the LCD display via the I2C module, the programmer launched the program code, but there was nothing when displayed. Students downloaded the "LiquidCrystal_I2C.h" libraries from various sources, wrote program codes with different functions, increased and decreased the contrast of the display using the knob, but nothing worked. After many experiments 
and searches, students, integrating their knowledge, were still able to connect the LCD display. The reason for the lack of text on the display was the wrong I2C address. Different manufacturers can have default addresses protected (changed the device address from $0 \mathrm{x} 3 \mathrm{~F}$ or to $0 \times 27$ ).

After conducting project training in programming microcontrollers, participants formed a holistic view of the project, and awareness of the completeness and significance of their activities increased the students' self-esteem. Also, the participants learnt to apply theoretical knowledge to solve real world problems in practice and received an unforgettable experience working in team.
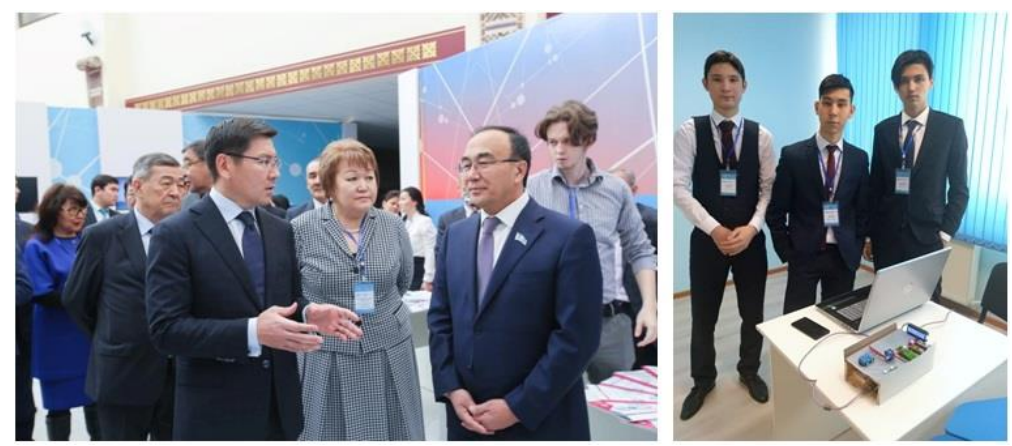

Fig. 4. Minister of Digital Development, Defense and Aerospace Industry of the Republic of Kazakhstan A.K. Zhumagaliev at the exhibition Digital ENU

\section{Conclusion}

Summing up the research, in the context of digitalization, the main vector for developing the educational process at the L.N. Gumilyov Eurasian National University is project-based research activities. The project-based research activities demonstrate visible results. Examples of such projects are "Smart parking" and "Smart garden", which were developed during the educational projects by students. These projects were presented to the Minister of Digital Development, Defense and Aerospace Industry of the Republic of Kazakhstan A.K. Zhumagaliev (Figure 4) at "Digital ENU" exhibition. This approach impressed Minister and was noted as "the best version of the teaching methodology" by the Minister.

\section{$5 \quad$ References}

[1] Nurbekova Zh.K., Tolganbaiuly T. Results of experimental-experimental work in the teaching of programming of microrobots. Abai Kazakh National Pedagogical University, bulletin of Pedagogical sciences №1(61), 2019

[2] Analysis of survey results for receiving feedback on the level of implementation of digital tools in higher educational institutions of the Republic of Kazakhstan, WP-1, T-2 (work 
package, task), Modernisation of higher education in Central Asia through new technologies, 2019

[3] Hochschulforum Digitalisierung THE DIGITAL TURN Pathways for higher education in the digital age. https://hochschulforumdigitalisierung.de/sites/default/files/dateien/HFD Final_Report_english.pdf

[4] ISO/IEC 12207:2008 «System and software engineering - Software life cycle processes» https://doi.org/10.3403/30236650

[5] ISO 21500:2012 - Guidance on project management

[6] Project Management Institute. A Guide to the Project Management Body of Knowledge Fifth edition, ISBN 978-1-935589-67-9, 2013

[7] Sahil Barjtya, Ankur Sharma, Usha Rani, A detailed study of Software Development Life Cycle (SDLC) Models. International Journal of Engineering and Computer Science ISSN:2319-7242, Volume 6 Issue 7 July 2017, Page No. 22097-22100

[8] Marco Antonio Carvalho Pereiraa, Maria Auxiliadora Motta Barretoa, Marina Pazetia. Application of Project-Based Learning in the first year of an Industrial Engineering Program: lessons learned and challenges, aUniversidade de Sго Paulo, Lorena, SP, Brasil, Print version ISSN 0103-6513On-line version ISSN 1980-5411, 2017

[9] Dr. Afsaneh Minaie, Dr. Reza Sanati-Mehrizy. Capstone Projects in a Computer Engineering Program Using Arduino. American Society for Engineering Education, Paper ID \#15299, ASEE's 123rd Annual, conference\&Exposition, june 26-29,2016 https://doi.org/ $\underline{10.18260 / \text { p. } 26446}$

[10] Pablo Marthn-Ramos, M. Margarida Lima da Silva, Maria Jого Lopes, Manuela Ramos Silva. Student2student: Arduino Project-based Learning. Fourth International Conference on Technological Ecosystems for Enhancing Multiculturality - TEEM'16. November 02 04. 2016 https://doi.org/10.1145/3012430.3012500

[11] Petre Lucian Ogrutan. Increasing Students' Interest by Encouraging them to Create Original Lab Projects. TEM Journal. Volume 6, Issue 4, Pages 653-659, ISSN 2217-8309, DOI: 10.18421/TEM64-02. November 2017

[12] Kun Ma, Hao Teng, Lixin Du, and Kun Zhang, Project-Driven Learning-by-Doing Method for Teaching Software Engineering Using Virtualization Technology, International Journal of Emerging Technologies in Learning. Volume 9, Issue 9: "Blended Learning", 26-31. 2014. https://doi.org/10.3991/ijet.v9i9.4006

[13] S. Jacques, S. Bissey and A. Martin. Multidisciplinary Project Based Learning Within a Collaborative Framework A Case Study on Urban Drone Conception. International Journal of Emerging Technologies in Learning. Vol 11, No 12. 36-44 (2016). https://doi.org/10. $\underline{\text { 3991/ijet.v11i12.5996 }}$

[14] Yu.Yu. Kovalyova, A.V. Soboleva, A.T. Kerimkulov. Project Based Learning in Teaching Communication Skills in English as a Foreign Language to Engineering Students. International Journal of Emerging Technologies in Learning. Vol 11, No 04.253-156 (2016). https://doi.org/10.3991/ijet.v11i04.5416

[15] Nurbekova Zh.K., Tolganbaiuly T. Otbor sredy obuchenia programmiirovaniu mikrorobotov v vuze, XXIV International Scientific Conference «Current research in the modern world», GVUZ «Pereiaslav-Hmelinskii gosudarstvennyi pedagogicheskii universitet imeni Grigoria Skovorody. Pereiaslav-Hmelinskii. Ukraine, 2017

[16] Official website Arduino [Electronic resource]: https://www.arduino.cc/

[17] Massimo Banzi. Getting started with Arduino, Second edition. 2011

[18] N.F.Iakovleva. Proektnaia deiatelnost v obrazovatelnom uchrejdenii, uchebnoe posobie. 2014 
[19] Nurbekova Zh.K., N Tokzhigitova, B Nurbekov, G Jarassova, Multi-criteria Assessment of Students' Study Achievements in Visual Programming. Man, In India, 97 (13): 483-509

\section{Authors}

Zhanat Nurbekova, Doctor of Pedagogical Sciences, professor, Director of the Institute of Digitalization, L.N. Gumilyov Eurasian National University, 010000, NurSultan, Kazakhstan, nurbekova_zhk@enu.kz

Talant Tolganbaiuly, Senior Engineer, Department of Informatics and Information Security, L.N. Gumilyov Eurasian National University, 010000, Nur-Sultan, Kazakhstan, talant2101@gmail.com

Bahyt Nurbekov, Doctor of Pedagogical Sciences, professor, Faculty of Mechanics and Mathematics, L.N. Gumilyov Eurasian National University, 010000, Nur-Sultan, Kazakhstan, b_zh_nur@mail.ru

Ainur Sagimbayeva, Doctor of Pedagogical Sciences, professor of the Department of Informatics and Informatization of Education, Institute of Mathematics, Physics and Informatics, Abay Kazakh National Pedagogical University, 050000, Almaty, Kazakhstan, aiya_c@mail.ru

Zhadira Kazhiakparova, Associate Professor of the Department of "Natural Scientific Disciplines", West Kazakhstan Innovation Technology University, 090000, Uralsk, Kazakhstan, ghadira@ rambler.ru

Article submitted 2020-01-20. Resubmitted 2020-02-25. Final acceptance 2020-02-26. Final version published as submitted by the authors. 